\title{
Low serum levels of meteorin-like/subfatin: an indicator of diabetes mellitus and insulin resistance?
}

\author{
Erhan Onalan', Cundullah Cavlı', Yusuf Dogan', Ebru Onalan², Nevzat Gozel', ilay Buran², \\ Burkay Yakar ${ }^{3}$, Emir Donder ${ }^{1}$
}

${ }^{1}$ Department of Internal Medicine, Faculty of Medicine, Firat University, Elazig, Turkey

${ }^{2}$ Department of Medical Biology, Medical Faculty, Firat University, Elazig, Turkey

${ }^{3}$ Department of Family Medicine, Faculty of Medicine, Firat University, Elazig, Turkey

\begin{abstract}
Introduction: Meteorin-like (Metrnl), also known as subfatin, is a recently discovered adipokine with a favourable effect on insulin sensitivity. Studies have shown lower Metrnl levels in obese patients. However, data on its circulating levels in type 2 diabetes mellitus (T2DM) patients are contradictory. This study aims to evaluate serum Metrnl levels in T2DM patients and determine the relationship between serum Metrnl levels and insulin resistance in these patients.

Material and methods: This cross-sectional study was conducted among 150 participants. The study was carried out between June 2019 and December 2019 at the internal medicine outpatient clinic of a tertiary university hospital. The participants were divided into three groups: group 1 (control group, $\mathrm{n}=50$ ), group 2 (newly diagnosed T2DM, $\mathrm{n}=50$ ), and group 3 (long-standing diagnosed T2DM, $\mathrm{n}=$ 50). An enzyme-linked immunosorbent assay (ELISA) was used to measure the serum levels of Subfatin (Metrnl), and the correlations of Metrnl level with anthropometric parameters, HOMA index, and biochemical measurements were assessed.

Results: There was no statistically significant difference between the gender $(p=0.468)$ and age $(p=0.067)$ characteristics of the three groups. The Metrnl (subfatin) levels of the participants were as follows: control group - 20.05 (1.56-103.78); newly diagnosed T2DM group - 2.62 (1.25-103.78); and long-standing diagnosed T2DM group - 2.01 (0.80-19.84) pg/mL. The Metrnl (subfatin) levels of the participants in the control group were higher than in the participants in the newly diagnosed T2DM and long-standing diagnosed T2DM groups ( $p$ $<0.001)$. Subfatin demonstrated a negative correlation with insulin and HOMA-IR in the control group and long-standing diagnosed T2DM group.

Conclusions: The subfatin level was found to be higher in the healthy control group than in both diabetic patient groups. Subfatin level showed negative correlation with both insulin level and HOMA index. There was a relationship between subfatin and insulin resistance. Low levels of subfatin in the diabetic patient groups may play a role in the pathogenesis of T2DM by increasing insulin resistance. (Endokrynol Pol 2020; 71 (5): 397-403)
\end{abstract}

Key words: subfatin/meteorin-like; type 2 diabetes mellitus; insulin resistance; newly diagnosed T2DM

\section{Introduction}

Diabetes mellitus (DM) is a disease characterised by vascular and neuropathic complications, in which carbohydrates, lipids, and proteins cannot be metabolised optimally due to insulin deficiency or problems related to insulin [1].

Subfatin, also known as Metrnl, is a recently discovered adipokine. It is secreted by white adipose tissue and skeletal muscles [2-5]. Findings have shown that subfatin is secreted at higher concentrations from white and brown adipose tissues during exposure to cold and that it induces thermogenesis-associated genes [5]. Subfatin increases anti-inflammatory cytokines by promoting interleukin 4 (IL-4) expression. Moreover, there is some evidence suggesting that Metrnl has favourable effects on insulin sensitivity [4-6]. Subfatin (meteorin-like) controls insulin sensitivity via local autocrine/paracrine effects on the peroxisome proliferator-activated receptor-gamma (PPAR- $\gamma$ ) pathway [7]. The subfatin gene is located on chromosome 11qE2 in mice and on chromosome 17q25.3 in humans [3-5]. The subfatin protein is produced in white adipose tissues and skeletal muscles $[3,8]$ and consists of 266 amino acids, with a molecular weight of approximately $30 \mathrm{kDa}$ [8]. Mouse and human subfatin genes have $77 \%$ sequence similarity [5]. Adipocyte-induced insulin resistance develops in the absence or insufficiency of subfatin [7]. Serum subfatin levels in type 2 diabetes patients are significantly reduced, have a negative correlation with glucose levels, and contribute to the worsening of glucose tolerance [9, 10]. In two other studies, subfatin levels were reported to 
increase in patients with prediabetes and type 2 diabetes compared to control patients [11, 12]. Subfatin induces phosphorylation in the adipocyte tissue and increases insulin sensitivity, and its deficiency was found to cause insulin resistance in adipocyte tissue. Meanwhile, data on its circulating levels in type 2 diabetes mellitus (T2DM) patients are inconsistent [13,3]. Subfatin is a recently discovered adipokine with a favourable effect on insulin sensitivity and studies have shown lower levels in obese patients. However, there are scarce and conflicting data with regard to type 2 diabetes mellitus (T2DM), and more comprehensive studies are needed. In this study, we aimed to determine whether or not subfatin levels could serve as a useful marker for insulin resistance in diabetic patients.

\section{Material and methods}

This cross-sectional study was conducted in the internal medicine outpatient clinic of a tertiary university hospital between June 2019 and December 2019. Ethical approval was obtained from the Ethics Committee of Non-Interventional Research of Firat University (22.11.2018/14). Those who met the inclusion criteria were included in the study, and written consent form was obtained from all participants.

\section{Patients and control subjects}

This observational study included 150 participants. Three groups were studied that included a group of newly diagnosed T2DM patients who were not on medical treatment (group 2) $(n=50)$, a group with long-standing diagnosed type 2 diabetes mellitus who were on medical treatment (group 3) $(\mathrm{T} 2 \mathrm{DM})(\mathrm{n}=50)$, and control group of healthy participants (group 1$)(n=50)$. The newly diagnosed T2DM group were identified as patients who had been T2DM diagnosed in the preceding three months and had not yet had drug treatment for diabetes. The long-standing T2DM group were defined as patients who had been diagnosed with T2DM for at least five years and had been on drug medication for diabetes. The long-standing T2DM group was selected among patients who did not use insulin. All patients in the long-standing T2DM group were selected from patients using metformin and gliclazide for diabetes treatment.

The study inclusion criteria were as follows: (1) having T2DM diagnosis according to 1999 World Health Organisation diagnostic and classification criteria; (2) a glycosylated haemoglobin $\left(\mathrm{HbA}_{1 \mathrm{c}}\right)$ value between 6.0 and $13.0 \%$; and (3) being over 30 years old.

The exclusion criteria were as follows: (1) having type 1 DM diagnosis; (2) patients receiving different treatment protocols other than inclusion criteria; (3) having chronic hypertension disease; (4) having congenital anomaly, liver disease, chronic renal disease, acute infection, or hypothyroidism; (5) having malignancy; (6) having psychiatric and neurological diseases that affect cognitive functions.

\section{Data collection}

Demographic and biochemical parameters of the participants were questioned in the study. Age, gender, duration of T2DM, and drugs used by the participants were recorded in the questionnaire form. The anthropometric measurements of the participants (height, weight, and waist and hip circumference) were measured by the same researcher. The standing height of patients was measured with a linear height scale with sensitivity of $0.1 \mathrm{~cm}$, and weight was measured in lightweight clothing to the nearest $0.1 \mathrm{~kg}$ with a sensitive digital scale. The waist circumference was measured at minimal inspiration to the nearest $0.1 \mathrm{~cm}$, midway between the last rib and the iliac crest. Hip circumferences were measured at the level of the anterior superior iliac spine, where this could be felt, otherwise at the broadest circumference below the waist. Body mass index (BMI) was calculated by dividing body weight by the square of the height $\left[\mathrm{kg} / \mathrm{m}^{2}\right]$. The blood pressure of all participants was measured with an aneroid sphygmomanometer from both arms after a rest period of at least 15 minutes then the mean blood pressure was recorded.

\section{Collection and storage of biological samples}

After at least 10 hours of overnight fasting, a sample of fasting venous blood was collected, and the serum was used for the measurement of fasting blood glucose (FBG), fasting insulin, total cholesterol (TC), triglyceride (TG), low-density lipoprotein cholesterol (LDL-C), alanine aminotransferase (ALT), aspartate aminotransferase (AST), and creatinine by using an automatic biochemical analyser (FUJI DRI-CHEM 4000i, Fuji, Japan). Glycated haemoglobin ( $\mathrm{HbA}_{1 \mathrm{c}}$ ) concentration was measured by high-performance liquid chromatography (HPLC) using a VARIANT ${ }^{\mathrm{TM}}$ II TURBO (Bio-Rad Laboratories, Inc., Hercules, CA, USA). Serum levels of insulin were determined using UniCel DxI 800 Access Immunoassay System (Beckman Coulter, Inc., Brea, CA, USA). Fasting glucose and fasting insulin levels were then used to estimate insulin resistant state and $\beta$-cell function, as follows:

\section{HOMA-IR $[\mathrm{mg} / \mathrm{dL}]=[$ fasting insulin $(/ \mathrm{mL})$ $\times$ Fasting glucose $(\mathrm{mg} / \mathrm{dL}) / 405][14]$}

Blood sample was collected into EDTA tubes for haemoglobin measurement. Haemoglobin measurements with the automated analyser in the laboratory (Coulter Hmx Haematology Flow Cytometer, Beckman Inc., CA, USA) were performed in accordance with our standard clinical practice

\section{Measurement of serum subfatin (Metrnl) levels}

Blood samples were collected into aprotinin tubes were stored at $-20^{\circ} \mathrm{C}$ after centrifugation until they were analysed. Serum subfatin (Metrnl) levels were measured using enzyme-linked immunosorbent assay (ELISA) kits (Code: 201-12-9252) (Bioassay Technology Laboratory Shanghai, China). The intra-assay coefficient of variation values of ELISA kits were less than $8 \%$, while the inter-assay coefficient of variation values were less than $10 \%$. The measuring range (standard curve) of the subfatin kit was $0.05-15 \mathrm{ng} / \mathrm{mL}$, and the minimum measurable level (sensitivity) was $0.023 \mathrm{ng} / \mathrm{mL}$.

\section{Statistical analyses}

Statistical analysis of the data was performed by IBM SPSS 22 statistics package software. The Shapiro-Wilk test was used to determine whether the data showed normal distribution. Descriptive statistics of the data were expressed as mean \pm standard deviation for variables with normal distribution in continuous data, [median (minimum: maximum) for non-normal distribution variables, and frequency for categorical variables as percentage $(n(\%)]$. Categorical variables were compared using chi-squared tests. In the comparison of more than two independent groups, one-way ANOVA and LSD test for post hoc testing were used for normally distributed continuous data, and the Kruskal-Wallis test and Dunn tests were used for post hoc testing for non-normally distributed continuous data. For the relationship between two sets of continuous data, Pearson correlation analysis was used for normally distributed continuous data and Spearman's correlation analysis was used for non-normally distributed variables. The significance level was $\alpha=0.05$.

\section{Results}

A total of 150 participants included in the study were divided into three groups. There was no statistically signifi- 
cant difference in gender $(\mathrm{p}=0.468)$ and age $(\mathrm{p}=0.067)$ characteristics between the three groups. Compared with the control group, the group with newly diagnosed T2DM and the long-standing diagnosed T2DM group had significantly higher BMI $(\mathrm{p}<0.001)$, FBG $(\mathrm{p}<0.001)$, $\mathrm{HbA}_{1 \mathrm{c}}(\mathrm{p}<0.001)$, total cholesterol $(\mathrm{p}<0.001)$, LDL-C
( $p<0.001)$, and triglyceride $(\mathrm{p}<0.001)$ levels. Compared with the newly diagnosed T2DM and long-standing diagnosed T2DM groups, the control group had significantly higher Metrnl (subfatin) levels ( $p<0.001$ ). The details of the anthropometric and biochemical data of the study population are given in Table 1 .

Table 1. Anthropometric and metabolic parameters of the studied population

\begin{tabular}{|c|c|c|c|c|c|}
\hline Variables & $\begin{array}{l}\text { Group } 1 \\
(n=50)\end{array}$ & $\begin{array}{l}\text { Group } 2 \\
(n=50)\end{array}$ & $\begin{array}{l}\text { Group } 3 \\
(n=50)\end{array}$ & $\mathbf{p}^{*}$ value & $\mathbf{p}^{* *}$ value \\
\hline & & & & & $1-2: 0.288$ \\
\hline \multirow[t]{2}{*}{ Age [years] } & $49.94 \pm 12.51^{1}$ & $52.42 \pm 12.57^{2}$ & $55.38 \pm 9.49^{3}$ & 0.067 & 1-3: 0.051 \\
\hline & & & & & 2-3: 0.205 \\
\hline \multicolumn{6}{|l|}{ Gender } \\
\hline Female $\mathrm{n}(\%)^{*}$ & $26(29.5)$ & $30(34.1)$ & $32(36.4)$ & 0.468 & \\
\hline Male $n(\%)^{*}$ & $25(38.7)$ & $20(32.3)$ & $18(29.0)$ & & \\
\hline DM duration (mean \pm SD) & $1.78 \pm 0.74^{\mathrm{a}}$ & $8.22 \pm 1.92^{\mathrm{a}}$ & $0.00 \pm 0.0$ & & \\
\hline \multirow{3}{*}{ BMI $\left[\mathrm{kg} / \mathrm{m}^{2}\right]$} & & & & & $1-2:<0.001$ \\
\hline & $25.37 \pm 3.36^{1}$ & $29.47 \pm 4.35^{2}$ & $30.84 \pm 5.18^{3}$ & $<0.001$ & $1-3:<0.001$ \\
\hline & & & & & $2-3: 0.120$ \\
\hline \multirow{3}{*}{ SBP $[\mathrm{mm} \mathrm{Hg}]$} & & & & & $1-2: 0.573$ \\
\hline & $120.50 \pm 10.06^{1}$ & $121.80 \pm 11.68^{2}$ & $120.40 \pm 12.65^{3}$ & 0.795 & $1-3: 0.975$ \\
\hline & & & & & 2-3: 0.544 \\
\hline \multirow{3}{*}{ DBP [mm Hg] } & & & & & 1-2: 0.607 \\
\hline & $74.50 \pm 6.56^{1}$ & $73.70 \pm 8.62^{2}$ & $74.10 \pm 7.93^{3}$ & 0.876 & 1-3: 0.797 \\
\hline & & & & & 2-3: 0.797 \\
\hline FBG [mg/dL] & $\begin{array}{c}91.00^{1} \\
(61.0-110.0)\end{array}$ & $\begin{array}{c}127^{2} \\
(88.0-407.0)\end{array}$ & $\begin{array}{c}157.50^{3} \\
(82.0-352.0)\end{array}$ & $<0.001$ & $\begin{array}{c}1-2:<0.001 \\
1-3:<0.001 \\
2-3: 0.860\end{array}$ \\
\hline Insulin [uU/mL] & $\begin{array}{c}6.80^{1} \\
(2.90-22.80)\end{array}$ & $\begin{array}{c}13.30^{2} \\
(3.93-181.00)\end{array}$ & $\begin{array}{c}9.45^{3} \\
(2.00-47.30)\end{array}$ & $<0.001$ & $\begin{array}{c}\text { 1-2: }<0.001 \\
1-3: 1.01 \\
\text { 2-3: } 0.001\end{array}$ \\
\hline HOMA-IR (index) & $\begin{array}{c}1.41^{1} \\
(0.60-5.12)\end{array}$ & $\begin{array}{c}4.60^{2} \\
(0.98-59.00)\end{array}$ & $\begin{array}{c}3.21^{3} \\
(0.86-33.80)\end{array}$ & $<0.001$ & $\begin{array}{c}1-2:<0.001 \\
1-3: 0.214 \\
2-3: 0.003\end{array}$ \\
\hline $\mathrm{HbA}_{1 \mathrm{c}}(\%)$ & $5.24 \pm 0.29$ & $8.09 \pm 2.35$ & $8.31 \pm 2.25$ & $<0.001$ & $\begin{array}{c}1-2:<0.001 \\
1-3:<0.001 \\
2-3: 0.565\end{array}$ \\
\hline Total cholesterol [mg/dL] & $172.50 \pm 29.99^{1}$ & $195.64 \pm 39.19^{2}$ & $206.26 \pm 34.07^{3}$ & $<0.001$ & $\begin{array}{c}1-2:<0.001 \\
1-3: 0.001 \\
2-3: 0.127\end{array}$ \\
\hline LDL-C [mg/dL] & $100.58 \pm 25.51^{1}$ & $126.68 \pm 38.06^{2}$ & $131.88 \pm 32.43^{3}$ & $<0.001$ & $\begin{array}{c}1-2:<0.001 \\
1-3:<0.001 \\
2-3: 0.424\end{array}$ \\
\hline \multirow{3}{*}{ HDL-C [mg/dL] } & & & & & $1-2: 0.182$ \\
\hline & $37.82 \pm .74$ & $36.30 \pm 4.76$ & $36.74 \pm 3.17$ & 0.193 & $1-3: 0.420$ \\
\hline & & & & & 2-3: 0.865 \\
\hline
\end{tabular}


Table 1. Anthropometric and metabolic parameters of the studied population

\begin{tabular}{|c|c|c|c|c|c|}
\hline Variables & $\begin{array}{l}\text { Group } 1 \\
(n=50)\end{array}$ & $\begin{array}{l}\text { Group } 2 \\
(n=50)\end{array}$ & $\begin{array}{l}\text { Group } 3 \\
(n=50)\end{array}$ & $\mathbf{p}^{*}$ value & $\mathbf{p}^{* *}$ value \\
\hline Triglyceride [mg/dL] & $\begin{array}{c}83.50^{1} \\
(41.0-225.0)\end{array}$ & $\begin{array}{c}162.00^{2} \\
(51.0-447.0)\end{array}$ & $\begin{array}{c}153.0^{3} \\
(53.0-524.0)\end{array}$ & $<0.001$ & $\begin{array}{c}1-2:<0.001 \\
1-3:<0.001 \\
2-3: 0.594\end{array}$ \\
\hline Creatinine [mg/dL] & $0.73 \pm 0.15^{1}$ & $0.79 \pm 0.20^{2}$ & $0.77 \pm 0.24^{3}$ & 0.307 & $\begin{array}{l}1-2: 0.130 \\
1-3: 0.328 \\
2-3: 0.590\end{array}$ \\
\hline AST [U/L] & $19.68 \pm 4.11^{1}$ & $27.34 \pm 14.61^{2}$ & $23.02 \pm 8.21^{3}$ & 0.013 & $\begin{array}{l}\text { 1-2: } 0.010 \\
1-3: 0.987 \\
\text { 2-3: } 0.011\end{array}$ \\
\hline ALT [U/L] & $23.88 \pm 8.33^{1}$ & $27.34 \pm 14.61^{2}$ & $23.02 \pm 8.21^{3}$ & 0.110 & $\begin{array}{l}1-2: 0.112 \\
1-3: 0.691 \\
2-3: 0.058\end{array}$ \\
\hline Haemoglobin & $13.95 \pm 1.38^{1}$ & $13.96 \pm 1.47^{2}$ & $14.35 \pm 1.32^{3}$ & 0.282 & $\begin{array}{l}1-2: 0.977 \\
1-3: 0.158 \\
2-3: 0.167\end{array}$ \\
\hline $\begin{array}{l}\text { Metrnl [pg/mL] } \\
\text { (subfatin) }\end{array}$ & $\begin{array}{c}20.05^{1} \\
(1.56-103.78) \\
(21.16 \pm 17.09)\end{array}$ & $\begin{array}{c}2.62^{2} \\
(1.25-103.78) \\
(5.62 \pm 14.59)\end{array}$ & $\begin{array}{c}2.01^{3} \\
(0.80-19.84) \\
(2.81 \pm 2.85)\end{array}$ & $<0.001$ & $\begin{array}{c}1-2:<0.001 \\
1-3:<0.001 \\
2-3: 0.285\end{array}$ \\
\hline
\end{tabular}

Group 1 - control group; Group 2 - newly diagnosed type 2 diabetes mellitus (DM); Group 3 - long-standing diagnosed type 2 DM; *row percentages; $\mathrm{p}^{*}$ - multiple comparison $\mathrm{p}$ value; $\mathrm{p}^{* *}$ — binary comparison $\mathrm{p}$ value, BMI — body mass index; SBP — systolic blood pressure; DBP — diastolic blood pressure; FBG — fasting blood glucose; $\mathrm{HbA}_{1 \mathrm{c}}$ — glycated haemoglobin; LDL-C — low-density lipoprotein cholesterol; ALT — alanine aminotransferase; AST — aspartate aminotransferase, aduration of newly diagnosed T2DM (months); ${ }^{b}$ duration of long-standing T2DM (years)

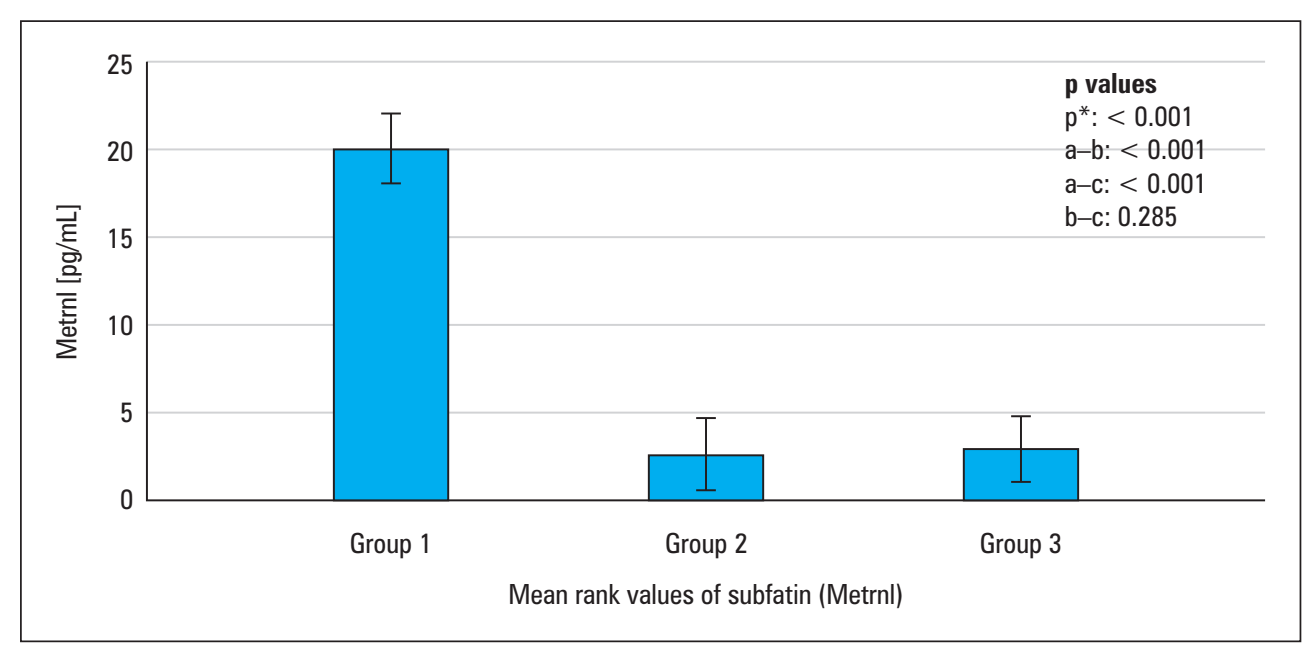

Figure 1. Comparison of subfatin levels between groups. $p^{*}-$ multiple comparison $p$ value, $a-b-$ comparison between control and newly diagnosed type 2 diabetes mellitus (DM); $a-c$ - comparison between control and T2DM; $b-c$ - comparison between newly diagnosed T2DM and T2DM; Group 1 - control group; Group 2 - newly diagnosed type 2 DM; Group 3 - long-standing diagnosed type $2 D M$

The Metrnl (subfatin) levels of the participants were as follows: control group - 20.05 (1.56-103.78); newly diagnosed T2DM group - 2.62 (1.25-103.78); and long-standing diagnosed T2DM group - 2.01 (0.80-19.84) $\mathrm{pg} / \mathrm{mL}$. The Metrnl (Subfatin) levels of the participants in the control group were higher than in participants in the newly diagnosed T2DM and long-standing diagnosed T2DM groups ( $\mathrm{p}<0.001$ ) (Fig. 1).

Correlation analysis was performed in three studied populations. Subfatin demonstrated a negative 
Table 2. Correlation analysis of serum levels of subfatin (Metrnl) with anthropometric and biochemical data

\begin{tabular}{|c|c|c|c|}
\hline Variables & $\begin{array}{c}\text { Group } 1 \\
(\mathrm{n}=50)\end{array}$ & $\begin{array}{c}\text { Group } 2 \\
(\mathrm{n}=50)\end{array}$ & $\begin{array}{c}\text { Group } 3 \\
(n=50)\end{array}$ \\
\hline Age & -0.169 & -0.261 & 0.046 \\
\hline $\mathrm{BMI}$ & 0.126 & 0.058 & 0.052 \\
\hline SBP & -0.008 & 0.096 & 0.227 \\
\hline DBP & -0.265 & 0.157 & 0.152 \\
\hline $\mathrm{FBG}$ & -0.050 & $-0.330^{*}$ & $-0.374^{* *}$ \\
\hline Insulin & $-0.287^{*}$ & -0.252 & $-0.287^{*}$ \\
\hline HOMA-IR & $-0.288^{*}$ & -0.254 & $-0.372^{* *}$ \\
\hline TC & -0.049 & 0.017 & 0.006 \\
\hline LDL-C & -0.223 & -0.156 & 0.090 \\
\hline HDL-C & 0.163 & 0.101 & -0.223 \\
\hline $\mathrm{Cr}$ & -0.092 & -0.122 & 0.222 \\
\hline AST & 0.149 & -0.020 & -0.039 \\
\hline ALT & 0.189 & 0.110 & -0.094 \\
\hline $\mathrm{HbA}_{1 \mathrm{c}}$ & -0.077 & -0.177 & $-0.320^{* *}$ \\
\hline
\end{tabular}

Table 3. Correlation analysis between serum levels of subfatin (Metrnl) and body mass index (BMI)

\begin{tabular}{llc}
\hline & & BMI $\left[\mathrm{kg} / \mathrm{m}^{2}\right]$ \\
\hline Subfatin $[\mathrm{pg} / \mathrm{mL}]$ & $\mathrm{r}^{* *}$ & $-.393^{* *}$ \\
\hline $\mathrm{n}$ & $<0.001$ \\
\hline $\mathrm{r}^{*}$ - correlation coefficient; $\mathrm{p}^{* *}$ - statistical significance value
\end{tabular}

correlation with insulin and HOMA-IR in the control group and long-standing diagnosed T2DM group, and a negative correlation with fasting glucose in the newly diagnosed T2DM and long-standing diagnosed T2DM groups. Subfatin demonstrated a negative correlation with $\mathrm{HbA}_{1 \mathrm{c}}$ in the long-standing diagnosed T2DM group (Tab. 2).

When the relationship between subfatin and BMI was examined without discriminating between groups, there was a significant negative correlation between subfatin levels and BMI (Tab. 3).

\section{Discussion}

Subfatin, is a novel adipokine that is secreted from skeletal muscle and adipose tissue, and it is thought to play a role in metabolic and inflammatory diseases [5]. In this context, the relationship between subfatin and T2DM has been the subject of current research. There have been several reported studies on the association between serum levels of subfatin in T2DM, but the findings are controversial.

In our study, subfatin levels in the control, newly diagnosed T2DM, and long-standing diagnosed T2DM patient groups were $21.16 \pm 17.09,5.62 \pm 14.59$, and $2.81 \pm 2.85 \mathrm{pg} / \mathrm{mL}$, respectively. In the present study, we found that the subfatin concentration was distinctly decreased in patients with type 2 diabetes mellitus compared the healthy control group. Similar to the findings we obtained in three different studies in the literature, subfatin levels were reported to be lower in T2DM patients compared to the control group $[9,10$, 14]. In contrast with our study, Chung et al. reported that the circulating levels of subfatin were increased in patients with T2DM [11]. Chung et al. selected the study population from the Korean sarcopenic obesity study involving patients with sarcopaenia and therefore may have obtained different results than our study. It has been shown that subfatin is secreted by skeletal muscle in humans and mice [6]. Therefore, sarcopaenia could be a confounding factor in the Chung et al. study, which affected the circulating levels of subfatin. Although the relationship between T2DM and subfatin levels is controversial, it can be said that subfatin levels decreased in T2DM patients based on the data we obtained and from the literature.

Subfatin may play an important role in T2DM pathogenesis with its effect on insulin resistance. The underlying reason for investigating the relationship between subfatin and T2DM is due to the effect of 
a new molecule, subfatin, on insulin sensitivity. Studies in mice have shown that subfatin could increase insulin sensitivity by stimulating the peroxisome proliferator-activated receptor gamma (PPARg) pathway, which plays a regulatory role in insulin resistance and adipocyte differentiation [7]. Due to this effect of subfatin on insulin sensitivity and resistance, it is expected to show a negative correlation with the HOMA index. In the current study, the HOMA index of the control group with high subfatin level was lower than that of both diabetic patient groups. In similar studies in the literature comparing diabetic patients with control groups, the HOMA index was lower in the control group with higher subfatin levels than diabetic patients group [10-12]. Our data were similar to the literature and an inverse relationship was found between subfatin level and insulin resistance. In the correlation analysis between subfatin and HOMA index, there was a negative correlation in both control and diabetic patients. In the literature, two studies report a negative correlation between subfatin level and insulin resistance in both diabetic patients and control groups [14, 15]. Dadmanesh et al. reported that Metrnl was found to be correlated with insulin resistance and the parameter of glucose and insulin metabolism in T2DM patients, but Metrnl showed a negative correlation with HOMA-IR in the control; however, this correlation disappeared after adjusting for age and sex [9]. The common point of the literature data and the data we obtained is the detection of a negative correlation between HOMA index and subfatin levels in the diabetic patient group.

Subfatin is expected to affect other metabolic and biochemical parameters besides insulin resistance. Chung et al. reported that circulating Metrnl levels in human subjects were inversely associated with metabolic parameters, including SBP, DBP, total cholesterol, LDL cholesterol, triglycerides, and fasting plasma glucose [11]. In our study, there was no statistically significant relationship between subfatin level and biochemical parameters. The current study failed to explain the relationship between subfatin levels and biochemical parameters. In future studies, the relationship between biochemical parameters and subfatin levels should be investigated in a larger population.

Because subfatin is highly expressed in white adipose tissue, the subfatin level is expected to increase in those with high body mass index and waist circumference. In the current study, although the BMI in the diabetic patient groups was higher than in the control group, subfatin levels were lower than in the control group. Wang et al. reported that serum Metrnl levels were increased in overweight and obese subjects when compared with subjects of normal weight, and it was significantly correlated with BMI [7]. Löffler et al. also reported increased
Metrnl expression in adipocytes in obese children compared with lean children [16]. Our findings contradict data obtained by Wang and Löffler. Fadaei et al. reported that there was a statistical relationship between BMI and subfatin level in diabetic patients but no statistical relationship in the control group [10]. According to our data and the literature, the relationship between subfatin levels and obesity (BMI) requires further clinical study.

\section{Limitations}

This study had several limitations: firstly this current study was of cross-sectional design. Although there was no difference between the groups in terms of age and gender, the BMI of diabetic patients was higher than in the control group, which may affect subfatin levels. Long-standing diagnosed T2DM patients were selected from patients who had been treated for diabetes for at least five years. This observational study did not investigate the causal relationship between serum level subfatin and the development of T2DM. In addition, this study included only Turkish participants, and the findings may not apply to participants of different ethnic groups. Despite all our limitations, the present study included a relatively large number of subjects with comprehensive data on anthropometric factors, body composition, and laboratory measurements and thus can supplement the currently limited data about the role of subfatin in humans.

\section{Conclusion}

In our study, we compared healthy participants and diabetic patient groups, Subfatin levels were found to be higher in the healthy control group than in both diabetic patient groups. Subfatin level showed negative correlation with both insulin level and HOMA index. There was a relationship between subfatin and insulin resistance. Low levels of subfatin in diabetic patient groups may play a role in the pathogenesis of T2DM by increasing insulin resistance. Future mechanism research studies are required to explore the mechanism of subfatin in insulin resistance and T2DM.

\section{Declaration of conflicting interest}

The authors declare that there are no conflicts of interest.

\section{Funding}

This research received no external funding.

\section{References}

1. Diagnosis, Classification and Screening in Glycemic Disorders. TEMD Guidelines for Diagnosis, Treatment and Follow-up of Diabetes Mellitus and Complications. 9th ed. Turkish Endocrinology and Metabolism Association 2017. 
2. Rakugi H, Kamide K, Ogihara T. Vascular signaling pathways in the metabolic syndrome. Curr Hypertens Rep. 2002; 4(2): 105-111, doi: 10.1007/s11906-002-0034-1, indexed in Pubmed: 11884265.

3. Li ZY, Zheng SL, Wang P, et al. Subfatin is a novel adipokine and unlike Meteorin in adipose and brain expression. CNS Neurosci Ther. 2014; 20(4): 344-354, doi: 10.1111/cns.12219, indexed in Pubmed: 24393292.

4. Jørgensen JR, Fransson A, Fjord-Larsen L, et al. Cometin is a novel neurotrophic factor that promotes neurite outgrowth and neuroblast migration in vitro and supports survival of spiral ganglion neurons in vivo. Exp Neurol. 2012; 233(1): 172-181, doi: 10.1016/j.expneurol.2011.09.027, indexed in Pubmed: 21985865.

5. Zheng SL, Li ZY, Song J, et al. Metrnl: a secreted protein with new emerging functions. Acta Pharmacol Sin. 2016; 37(5): 571-579, doi: 10.1038/aps.2016.9, indexed in Pubmed: 27063217.

6. Rao RR, Long JZ, White JP, et al. Meteorin-like is a hormone that regulates immune-adipose interactions to increase beige fat thermogenesis. Cell. 2014; 157(6): 1279-1291, doi: 10.1016/j.cell.2014.03.065, indexed in Pubmed: 24906147.

7. Li ZY, Song J, Zheng SL, et al. Adipocyte Metrnl Antagonizes Insulin Resistance Through PPAR $\gamma$ Signaling. Diabetes. 2015; 64(12): 4011-4022 doi: 10.2337/db15-0274, indexed in Pubmed: 26307585.

8. Ushach I, Burkhardt AM, Martinez C, et al. METEORIN-LIKE is a cytokine associated with barrier tissues and alternatively activated macrophages. Clin Immunol. 2015; 156(2): 119-127, doi: 10.1016/j. clim.2014.11.006, indexed in Pubmed: 25486603.

9. Dadmanesh M, Aghajani H, Fadaei R, et al. Lower serum levels of Meteorin-like/Subfatin in patients with coronary artery disease and type 2 diabetes mellitus are negatively associated with insulin resis- tance and inflammatory cytokines. PLoS One. 2018; 13(9): e0204180, doi: 10.1371/journal.pone.0204180, indexed in Pubmed: 30212581.

10. Fadaei R, Dadmanesh M, Moradi N, et al. Serum levels of subfatin in patients with type 2 diabetes mellitus and its association with vascular adhesion molecules. Arch Physiol Biochem. 2018 [Epub ahead of print]: 1-6, doi: 10.1080/13813455.2018.1538248, indexed in Pubmed: 30463448.

11. Chung HS, Hwang SY, Choi JuH, et al. Implications of circulating Meteorin-like (Metrnl) level in human subjects with type 2 diabetes. Diabetes Res Clin Pract. 2018; 136: 100-107, doi: 10.1016/j.diabres.2017.11.031, indexed in Pubmed: 29199003.

12. Wang K, Li F, Wang C, et al. Serum Levels of Meteorin-Like (Metrnl) Are Increased in Patients with Newly Diagnosed Type 2 Diabetes Mellitus and Are Associated with Insulin Resistance. Med Sci Monit. 2019; 25: 2337-2343, doi: 10.12659/MSM.915331, indexed in Pubmed: 30928991.

13. Rakugi H, Kamide K, Ogihara T. Vascular signaling pathways in the metabolic syndrome. Curr Hypertens Rep. 2002; 4(2): 105-111, doi: 10.1007/s11906-002-0034-1, indexed in Pubmed: 11884265

14. Lee JuH, Kang YE, Kim JiM, et al. Serum Meteorin-like protein levels decreased in patients newly diagnosed with type 2 diabetes. Diabetes Res Clin Pract. 2018; 135: 7-10, doi: 10.1016/j.diabres.2017.10.005, indexed in Pubmed: 29097285.

15. Pellitero S, Piquer-Garcia I, Ferrer-Curriu G, et al. Opposite changes in meteorin-like and oncostatin $\mathrm{m}$ levels are associated with metabolic improvements after bariatric surgery. Int J Obes (Lond). 2018; 42(4): 919-922, doi: 10.1038/ijo.2017.268, indexed in Pubmed: 29081506.

16. Löffler D, Landgraf K, Rockstroh D, et al. METRNL decreases during adipogenesis and inhibits adipocyte differentiation leading to adipocyte hypertrophy in humans. Int J Obes (Lond). 2017; 41(1): 112-119, doi: 10.1038/ijo.2016.180, indexed in Pubmed: 27748745. 